\title{
Influence of atopy and asthma on exhaled nitric oxide in an unselected birth cohort study
}

\author{
Martha Scott, ${ }^{1,2}$ Abid Raza, ${ }_{1,2}^{1,2}$ Wilfried Karmaus ${ }^{3}$ Frances Mitchell, ${ }_{1}^{1}$ Jane Grundy, \\ Ramesh J Kurukulaaratchy, ${ }^{1,2}$ S Hasan Arshad, ${ }^{1,2}$ Graham Roberts ${ }^{1,2}$
}

${ }^{1}$ The David Hide Asthma and Allergy Research Centre, St Mary's Hospital, Newport, Isle of Wight, UK

${ }^{2}$ School of Medicine, University of Southampton, Southampton, UK

${ }^{3}$ Epidemiology and Biostatistics Department, Arnold School of Public Health, University of

South Carolina, Columbia, South Carolina, USA

\section{Correspondence to}

Dr Graham Roberts, The David Hide Asthma and Allergy Research Centre, St Mary's Hospital, Newport, Isle of Wight P030 5TG, UK;

g.c.roberts@soton.ac.uk

\section{ABSTRACT}

Background Asthma is considered to be associated with elevated levels of exhaled nitric oxide (FeNO). The nature of this relationship and how it is influenced by atopy are still not resolved.

Methods The Isle of Wight birth cohort $(N=1456)$ was reassessed at 18 years of age. Participants able to attend the research centre were assessed by questionnaires, skin prick testing and FeNO in order to explore the interrelationship between asthma, atopy and FeNO Results Atopy was significantly associated with higher levels of FeNO. However, the level of FeNO for nonatopic asthmatic participants was no different to the non-atopic no-asthma group. The highest levels of FeNO were seen in subjects with both atopy and asthma. In addition, FeNO was positively associated with increasing atopic burden as evidenced by increasing FeNO with increasing skin prick testing positivity, and with increasing severity of atopic asthma as evidenced by the number of attacks of wheezing. FeNO and current inhaled corticosteroid use were not significantly associated.

Conclusions FeNO behaves as a biomarker of atopy and the "allergic asthma" phenotype rather than asthma itself. This may explain why FeNO-guided asthma treatment outcomes have proved to be of limited success where atopic status has not been considered and accounted for.

\section{INTRODUCTION}

A relationship between the fraction of exhaled nitric oxide (FeNO) and asthma was demonstrated in the 1990s with the finding of elevated FeNO in patients with asthma. ${ }^{1-3}$ Further research suggested that FeNO was potentially a non-invasive marker of eosinophilic airways inflammation, ${ }^{4} 5$ with increased levels being seen with increasing allergen exposure. ${ }^{67}$ Studies found that FeNO levels rose in patients with asthma with worsening symptoms, suggesting that rising FeNO levels were a useful predictive marker of loss of control in subjects with asthma. ${ }^{8}$ Subsequently, rising FeNO levels and worsening spirometry were found to be significant predictors of asthma exacerbations. ${ }^{9}$ In addition, FeNO was found to be a better predictor of response to steroids than other markers such as peak expiratory flow readings, spirometry and bronchial hyper-responsiveness. ${ }^{10}$

The finding that FeNO levels are associated with asthma control has led to a number of studies examining whether FeNO can be used to guide asthma treatment. The results have been disappointing, with no significant advantage being associated with the specific use of FeNO-driven protocols compared with other methods. ${ }^{11-16} \mathrm{~A}$ potential explanation for this may be the presence of confounding or effect modification by atopy. Many of the studies looking at the relationship between asthma and FeNO enrolled mainly atopic patients with asthma. This was not taken into account when assessing the association between FeNO and asthma. ${ }^{1}{ }^{4}$ Where researchers have distinguished between atopic and non-atopic patients with asthma, significant differences have been found in FeNO levels with atopic patients with asthma having higher levels of FeNO. ${ }^{17}$ Further evidence for atopy being a significant influence on FeNO levels comes from epidemiological studies. In children with no history of respiratory problems, higher FeNO levels were found in atopic children and FeNO level correlated with the number of positive skin prick tests. ${ }^{18}$ Given that half of patients with asthma have coexistent atopy $^{19}$ and a quarter of the general population are atopic, ${ }^{20} 21$ it is important to assess how much of an influence atopy has on FeNO levels in patients with asthma and the general population. In this study we aimed to explore the combined effect of asthma and atopic status on FeNO.

\section{METHODS}

\section{Isle of Wight birth cohort study}

A whole population birth cohort study was established on the Isle of Wight in 1989 with the principal aim of prospectively studying the natural history of allergic disease from birth to young adulthood. Detailed descriptions of previous methodology, data collection and the results of previous study assessments at 1, 2, 4 and 10 years are given elsewhere. ${ }^{22}{ }^{23}$ Briefly, informed consent was obtained to follow-up 1456 children born between 1 January 1989 and 28 February 1990. Questionnaires were updated at all subsequent assessments with additional skin prick testing at 4 and 10 years and spirometry and methacholine challenge at 10 years.

Isle of Wight birth cohort study 18-year follow-up The local research ethics committee approved a further follow-up at 18 years and written consent was obtained from participants. Participants either attended the research centre or answered telephone or postal questionnaires. All participants answered the ISAAC core questionnaire ${ }^{24}$ and provided information on smoking. For those who attended the centre, data collection included height, weight and, where appropriate, additional questionnaires focusing on allergic symptoms. Skin prick testing 
was performed by a standardised method, ${ }^{25}$ identical to that used at the 10-year follow-up, to a panel of common aeroallergens and food allergens: house dust mite (Dermatophagoides pteronyssinus), grass pollen mix, tree pollen mix, cat and dog epithelia, Alternaria alternata, Cladosporium herbarum, milk, hens' egg, wheat, soya, cod and peanut and, in addition, histamine and physiological saline acted as the positive and negative controls respectively (Alk-Abello, Horsholm, Denmark). Single-headed lancets were used and the skin pricked at an angle of $90^{\circ}$. The weal diameter was recorded at $15 \mathrm{~min}$. FeNO was measured (Niox mino, Aerocrine AB, Solna, Sweden) according to American Thoracic Society (ATS) guidelines. ${ }^{26}$ A biofeedback mechanism was used to maintain the expiratory flow rate at $50 \mathrm{ml} / \mathrm{s}$ and subjects exhaled against resistance to prevent upper airway contamination. Measurements were made in a standardised manner with the subject standing without a nose clip; FeNO was measured before spirometric testing. Participants were rescheduled if they had clinical symptoms consistent with either current infection or a recent (within 2 weeks) asthma exacerbation, or had required antibiotics or oral steroids in the preceding 2 weeks.

\section{Definitions}

A participant was defined as atopic where they had at least one positive skin prick test to either a food or aeroallergen. A skin prick test was defined as positive where the mean diameter was at least $3 \mathrm{~mm}$ greater than the negative control. Groups based on number of positive skin prick tests ranged from 0 (no positive skin prick tests) to $>5$ positive skin prick tests. Asthma was defined using the ISAAC core questionnaire as: a positive answer to "ever had asthma" and either "wheeze in the last 12 months" or "current treatment in the last 12 months". Current inhaled corticosteroid use was determined by the participants' response to the questions: "Is your asthma treatment current?" and "Other asthma treatment-what?" Compliance with inhaled corticosteroids was defined as good if participants reported forgetting their preventive medication once a week or less and poor if they forgot more than this. Current rhinitis was defined using the ISAAC core questionnaires as: "Have you ever had a problem with sneezing, or a runny or a blocked nose when you did not have a cold or the flu" and "In the past 12 months have you had a problem with sneezing, or a runny or a blocked nose when you did not have a cold or the flu?" Asthma attacks were derived from the response to the question: "How many attacks of wheezing have you had in the last 12 months?" and were categorised as none, $1-3$ and $\geq 4$ attacks. Smoking status was defined by answers to the question: "Do you currently smoke?" Body mass index (BMI) was calculated by dividing weight $(\mathrm{kg})$ by height squared $\left(\mathrm{m}^{2}\right)$. Atopic status at 10-year follow-up was used to explore whether there were potential differences between attendees versus non-attendees in terms of atopy. Individuals were defined as being in full-time education if they were attending school, college or university full time.

\section{Analysis and statistical methods}

All statistical calculations were analysed using SPSS Version 17. We started the analysis by examining the interrelationship between atopy, current asthma and FeNO levels, as well as other factors (gender, smoking, height, BMI) that have been associated with FeNO in previous studies. We then focused on the relationship between asthma attacks, atopic status and FeNO. Lastly, we explored the relationship between FeNO and atopic "burden" by assessing the influence of increasing skin prick test positivity on FeNO.

Z-test of proportions was used to assess significant differences between participants who took part in this analysis versus the total population seen at age 18 years. FeNO values were logarithmically transformed to normalise the data. The adjusted logarithmic means of FeNO and their CIs were then converted to their geometric means and 95\% CIs; $t$ tests were used to test the significance of gender, smoking, asthma, current inhaled corticosteroid use and atopy on FeNO. The interrelationship between atopy, asthma and FeNO were further explored using a general linear method ANCOVA. All factors (height, BMI, atopic status, current asthma, gender and current smoking) were entered into a regression analysis with logarithmically-transformed FeNO as the dependent factor. The interaction between asthma and atopy was assessed within general linear models. Variables were considered significant with a $p$ value $<0.05$. A general linear model was used to explore any significant interactions between FeNO and atopy, smoking and compliance with inhaled corticosteroid use. A second model using ANOVA focused on the association between wheeze attacks in asthma, atopy and FeNO. When multiple tests were performed, $\mathrm{p}$ values were adjusted (Bonferroni correction). Finally, the association between FeNO and increasing skin prick testing positivity was explored using a general linear model (ANOVA) to assess whether there was a significant linear trend between increasing skin prick positivity and FeNO.

\section{RESULTS}

\section{Study population}

One thousand three hundred and thirteen $(90.2 \%$ ) of the original 1456 cohort members took part in the 18-year assessment; of these, 864 attended the centre and had their FeNO recorded and 449 completed either telephone or postal questionnaires. Full data of FeNO, atopic status, smoking status, height and BMI were available for 799 participants. Study participants were more likely to be in full-time education (table 1). For current asthma, rhinitis, eczema, smoking, gender and atopic status at 10 years there was no significant difference in the study participants and the whole population (table 1).

\section{Height, BMI, smoking, gender, atopy, asthma and FeNO}

Of the 864 participants who attended the centre, full data were available for 799. Male gender, atopy and asthma were all significantly $(p<0.001)$ associated with higher FeNO levels, while current smoking was associated with lower FeNO levels $(p<0.001)$ in unadjusted analyses. We did not find a significant association between inhaled corticosteroid use and FeNO levels (table 2).

To explore the interaction between atopy, asthma, rhinitis, gender, smoking, height and BMI, an ANCOVA model was developed where the main effects and significant interactions of the variables on FeNO were examined. Neither height $(p=0.466)$, BMI $(p=0.622)$ nor rhinitis $(p=0.094)$ was significantly

Table 1 Characteristics of participants in the study versus the whole population seen

\begin{tabular}{lrrr}
\hline & $\begin{array}{l}\text { Study } \\
\text { participants (n) }\end{array}$ & $\begin{array}{l}\text { Total population } \\
\text { at 18-year } \\
\text { follow-up (\%) }\end{array}$ & p Value* \\
\hline Female gender & $52.9 \%(423 / 799)$ & $50 \%(660 / 1313)$ & 0.196 \\
Active smoking & $24.7 \%(198 / 799)$ & $28 \%(368 / 1313)$ & 0.145 \\
Full-time education & $78 \%(624 / 799)$ & $68 \%(898 / 1313)$ & $<0.001$ \\
Atopic at 10† & $26.7 \%(189 / 709)$ & $26.9 \%(279 / 1036)$ & 0.956 \\
Asthma & $19.3 \%(155 / 799)$ & $17.5 \%(231 / 1313)$ & 0.6045
\end{tabular}

*Z-test of proportions (two-sided) for comparison between participants analysed in this study and all those assessed at 18 years of age.

†Numbers reflect those who attended at 10-year and at 18-year follow-up. 
Table 2 Association between gender, smoking, atopy, asthma and fraction of exhaled nitric oxide (FeNO)

\begin{tabular}{llll}
\hline Variable & & $\begin{array}{l}\text { FeNO (ppb), } \\
\text { geometric } \\
\text { mean (SD) }\end{array}$ & p Value* \\
\hline Gender & Male $(n=376)$ & $22(2)$ & $<0.001$ \\
& $\begin{array}{l}\text { Female }(n=423) \\
\text { Current smoking }\end{array}$ & $15(2)$ & \\
& Yes $(n=198)$ & $14(2)$ & $<0.001$ \\
Atopy & No $(n=601)$ & $19(2)$ & \\
& Yes $(n=324)$ & $28(2)$ & $<0.001$ \\
Asthma & No $(n=475)$ & $13(2)$ & \\
& Yes $(n=155)$ & $29(3)$ & $<0.001$ \\
Rhinitis & No $(n=644)$ & $16(2)$ & \\
& Yes $(n=310)$ & $25(2)$ & \\
Current inhaled corticosteroid use & No $(n=489)$ & $15(2)$ & 0.001 \\
in patients with asthma (n=155) & No $(n=90)$ & $30(3)$ & \\
\hline
\end{tabular}

*Two-sided $t$ test comparing logarithmically-transformed FeNO for each variable.

associated with FeNO levels. Smoking status was still significantly negatively associated with FeNO even after adjusting for other factors. We found that, once atopy, asthma and smoking had been taken into account, FeNO was no longer significantly different between men and women (geometric mean (95\% CI) 19 (17 to 22 ) and 18 (16 to 19 ), respectively; ANCOVA model $p=0.295)$. Furthermore, we found that there was a significant interaction between atopy and asthma $(p<0.001)$. When the interaction between asthma and atopic status was taken into consideration, FeNO levels were no longer significantly different between non-atopic asthmatic participants and those with neither atopy nor asthma (figure 1). Participants with atopy but no asthma had, on average, FeNO levels 7 ppb higher than those with non-atopic asthma $(\mathrm{p}<0.001)$. Meanwhile, atopic patients with asthma had levels $15 \mathrm{ppb}$ higher than those who were atopic but without asthma $(\mathrm{p}<0.001)$.

We used a general linear model to assess whether there was any interaction between FeNO, atopic status and compliance with inhaled corticosteroid use in patients with asthma, with adjustment for smoking. Inhaled corticosteroid treatment did not significantly influence FeNO levels irrespective of atopic status and compliance (table 3 ).

FeNO, wheeze attacks and atopy

Although the numbers were small, we found a dose-dependent relationship between the number of wheezing attacks in the

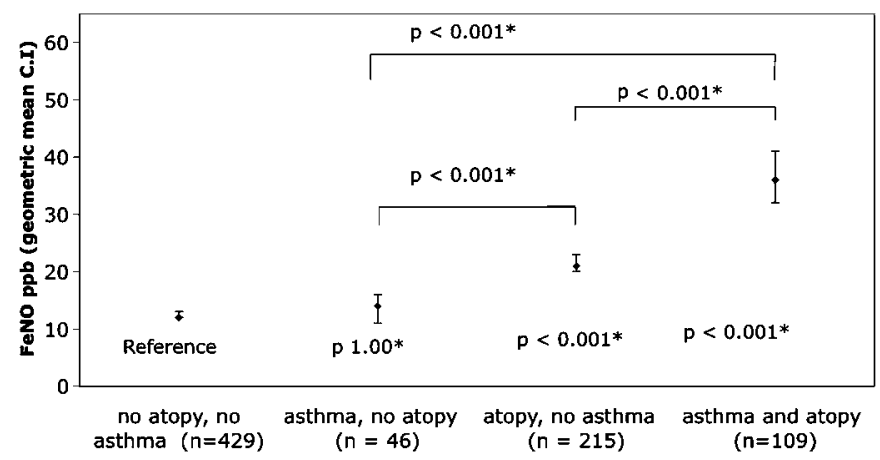

Figure 1 Fraction of exhaled nitric oxide (FeNO) and the influence of atopy and asthma; $p$ values below each marker refer to comparison with no asthma and no atopy with adjustment for smoking and gender using ANCOVA. The other $p$ values refer to the comparisons indicated by the marker using the ANCOVA model. * Bonferroni adjustment was used to correct for multiple comparisons.
Table 3 Fraction of exhaled nitric oxide (FeNO), atopy and compliance with inhaled corticosteroids

\begin{tabular}{llll}
\hline Asthma & $\begin{array}{l}\text { Inhaled } \\
\text { corticosteroids } \dagger\end{array}$ & $\begin{array}{l}\text { FeNO ppb* } \\
\text { mean }(\mathbf{9 5 \%} \text { CI) }\end{array}$ & p Value \\
\hline Atopic & Good compliance $(n=19)$ & $36(23$ to 56$)$ & 1.00 \\
No atopy & Poor compliance $(n=21)$ & $35(23$ to 52$)$ & \\
& Good compliance $(n=10)$ & $10(4$ to 22$)$ & 1.00 \\
& Poor compliance $(n=9)$ & $12(7$ to 21$)$ & \\
\hline
\end{tabular}

*Adjusted for smoking using general linear model ANOVA.

†Six participants did not provide information on compliance and were excluded.

previous year and FeNO in atopic patients with asthma but not in non-atopic patients with asthma (table 4). Furthermore, atopic patients with asthma had higher levels of FeNO than nonatopic patients whether they wheezed infrequently or frequently (table 4).

\section{Increasing skin prick positivity and FeNO}

Polynomial linear trend analysis in a general linear model showed that increasing numbers of positive skin prick tests to aeroallergens were associated with increasing FeNO $(p<0.001)$ (figure 2). The results were similar when food allergens were also included.

\section{DISCUSSION}

This study investigated the interrelationship between asthma, atopy and FeNO in a community sample of 864 young adults from the Isle of Wight 1989 birth cohort at 18 years of age. Both atopy and asthma were associated with higher levels of FeNO in this population within a univariant model. However, once interactions were taken into account, FeNO levels were more closely associated with atopy than asthma. Within the combined effect of asthma and atopy, increased FeNO levels were largely confined to atopic asthma (figure 1). We found that smoking was also significantly associated with FeNO but gender was not, once confounding due to atopy and asthma had been taken into account. As in other studies, we did not find height, ${ }^{27}{ }^{28} \mathrm{BMI}^{29}$ or rhinitis $^{30}$ to be significantly associated with FeNO after adjustment for other factors.

Inhaled corticosteroid use was not associated with any significant changes in FeNO in our community sample irrespective of atopic status. While we speculate that this may reflect that our participants have milder asthma and are on lower doses of inhaled corticosteroids than in studies of the impact of inhaled corticosteroids, ${ }^{31}$ our study is not of the right methodological design or size to be able to make firm comment.

Atopy is a key factor in FeNO levels since it is significantly associated with higher FeNO levels in both atopic asthmatic and atopic non-asthmatic patients (figure 1). In contrast, non-atopic participants showed no significant difference in FeNO levels whether they had asthma or not. A similar pattern was seen when looking at asthma attacks and atopy; FeNO increased with increasing frequency of exacerbations in atopic asthmatic patients but not in non-atopic patients with asthma (table 4). In addition, we found a significant association between increasing numbers of positive skin prick tests and increasing FeNO (figure 2), confirming previously published data. ${ }^{32}$

Thus, in the absence of atopy, patients with asthma do not significantly differ from those without asthma in terms of their mean FeNO. In addition, FeNO is significantly associated with increasing sensitisation as quantified by the number of positive skin prick tests. Taken together, these findings imply that FeNO is perhaps better thought of as a biomarker of the severity of atopic inflammation irrespective of the presence or absence of 
Table 4 Wheezing attacks in atopic versus non-atopic patients with asthma

\begin{tabular}{|c|c|c|c|c|c|}
\hline \multirow[b]{3}{*}{$\begin{array}{l}\text { Wheezing } \\
\text { attacks }\end{array}$} & \multicolumn{5}{|l|}{ FeNO (ppb) } \\
\hline & \multicolumn{2}{|c|}{ Atopic $(n=108 \ddagger)$} & \multirow{2}{*}{$\begin{array}{l}\text { Atopic vs } \\
\text { non- } \\
\text { atopic } \\
\text { p Value } \dagger\end{array}$} & \multicolumn{2}{|c|}{ Non-atopic $(n=45 \ddagger)$} \\
\hline & $\begin{array}{l}\text { Geometric } \\
\text { mean }(95 \% \mathrm{CI})\end{array}$ & p Value* & & $\begin{array}{l}\text { Geometric } \\
\text { mean ( } 95 \% \mathrm{CI})\end{array}$ & p Value* \\
\hline None & $\begin{array}{l}17(10 \text { to } 26) \\
\mathrm{n}=18\end{array}$ & Reference & $\mathrm{p}<0.05$ & $\begin{array}{l}10(6 \text { to } 17) \\
n=9\end{array}$ & Reference \\
\hline $1-3$ & $\begin{array}{l}34(28 \text { to } 42) \\
\mathrm{n}=60\end{array}$ & 1.00 & $\mathrm{p}<0.001$ & $\begin{array}{l}15(10 \text { to } 23) \\
n=21\end{array}$ & 1.00 \\
\hline$\geq 4$ & $\begin{array}{l}48(35 \text { to } 66) \\
n=30\end{array}$ & $<0.05$ & $\mathrm{p}<0.001$ & $\begin{array}{l}15(10 \text { to } 22) \\
n=15\end{array}$ & 1.00 \\
\hline
\end{tabular}

FeNO logarithmically transformed prior to analysis with results being back-transformed to give geometric means, with adjustment for smoking and gender.

*p Value for number of wheezing attacks compared with reference group adjusted for multiple comparisons (Bonferroni) using ANCOVA model.

tp Value for comparison between atopic and non-atopic patients with asthma using general linear model.

‡Two participants did not provide information on wheeze attacks and were excluded from this analysis.

asthma. However, within the context of atopy, coexistent asthma is associated with even higher FeNO levels. This may reflect that coexisting asthma is a marker of a more severe atopic phenotype consistent with the description by Haldar et $a l^{33}$ of an early onset atopic asthma phenotype characterised by high levels of FeNO and sputum eosinophils.

Our finding that FeNO is a marker of airway inflammation only in atopic asthma may explain the lack of success of studies $^{15} 16$ using FeNO to guide asthma therapy where atopic status has not been taken into account. In our study, wellcontrolled atopic patients with asthma (non-wheezers) had significantly higher FeNO levels than well-controlled non-atopic patients with asthma. In contrast, non-atopic patients with asthma with multiple wheezing attacks did not have significantly higher FeNO levels than atopic patients with asthma (table 4). It is plausible that using FeNO to drive anti-inflammatory asthma treatment in the symptomatic non-atopic asthma group would lead to undertreatment while overtreating those who were atopic and asymptomatic.

FeNO-guided treatment has also not proved to be successful in improving treatment in atopic patients with asthma. ${ }^{11}$ How then can we account for this? First, we have shown that multiple factors affect FeNO including atopy and increasing sensitisation.

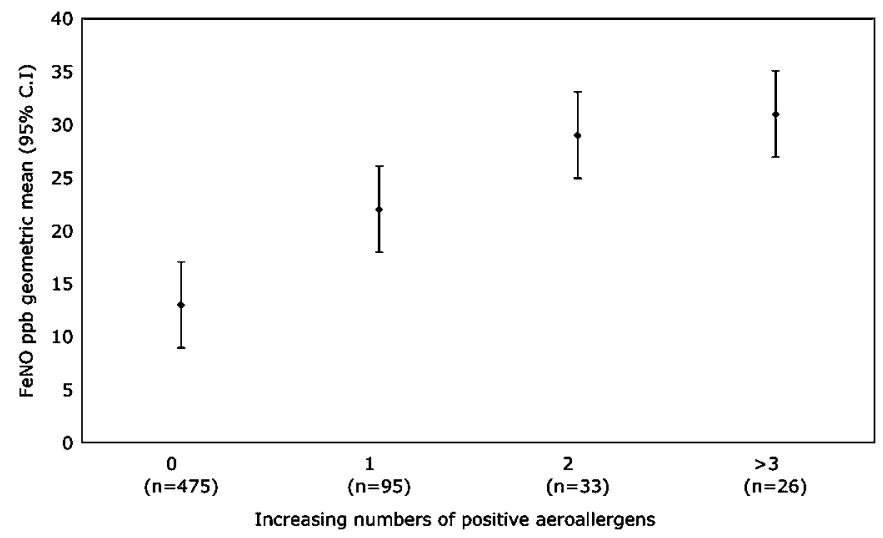

Figure 2 Fraction of exhaled nitric oxide (FeNO) and increasing skin prick positivity to aeroallergens. Markers are geometric mean FeNO values with $95 \% \mathrm{Cls}$. Increasing number of positive skin prick tests are significantly related to FeNO by polynomial linear trend analysis $(\mathrm{p}<0.001)$.
Given this, using one standardised cut-off value for FeNO to guide treatment may be too crude and potentially overtreat or undertreat individual patients. Second, we have shown that the presence of atopy alone is associated with elevated FeNO levels in patients without asthma and thus it is plausible that there are patients with asthma in whom elevated FeNO levels simply reflect the presence of atopy and are unrelated to asthma symptoms (the atopic well-controlled group in table 4). Our findings fit with the model of Haldar et al who reported two asthma sub-phenotypes with high FeNO levels, an "inflammation predominant" group with high FeNO levels and eosinophils but few symptoms and a concordant group with raised levels of FeNO and eosinophils in association with symptoms. ${ }^{33}$ Elevated $\mathrm{FeNO}$ in the former group seems only to reflect the presence of atopy, meaning that the current FeNO-driven asthma management strategies are only likely to be beneficial in the second concordant group.

Given that FeNO is influenced by a wide variety of factors including atopy, and that airway inflammation appears to be disconnected from asthma symptoms in some patients, it becomes increasingly difficult to see how FeNO-guided management strategies using standardised FeNO reference ranges can be successful, even in atopic patients with asthma An alternative would be to individualise the FeNO management strategy by determining each patient's baseline FeNO level while their asthma is well controlled. Rises from this level could then be used to appropriately direct anti-inflammatory therapy, as has been previously suggested. ${ }^{6}$

In this study participants who were in full-time education were more likely to have attended the centre, but there is no indication that this might have led to the introduction of bias into our results. Finally, we were not able to assess the effect of respiratory tract infections or asthma exacerbations as subjects only attended the centre if they were free from "cold" symptoms and had not required oral steroids in the preceding 2 weeks.

We have demonstrated that atopy plays a key role in determining FeNO levels, such that significantly elevated FeNO levels are not seen in the absence of atopy regardless of asthma status or symptoms. We have also provided data showing that the magnitude of FeNO may be influenced by an individuals "atopic burden", as evidenced by increasing FeNO levels with increasing skin prick testing positivity. It is therefore critical to know a patient's atopic status when interpreting FeNO levels. Furthermore, within the group of atopic patients with asthma, we suggest that there is a subgroup where FeNO levels may simply reflect the presence of atopy rather than reflecting asthma control or severity.

In conclusion, our findings are that FeNO within the whole population is influenced by the presence of atopy, the number of sensitisations and smoking status. In patients with asthma, it is only in the atopic phenotype that a significant relationship is seen between FeNO and increasing wheeze. FeNO in non-atopic patients with asthma is not significantly related to wheezing frequency, and this is an important finding given that nearly half of the patients with asthma are non-atopic. ${ }^{19}$ We speculate that using FeNO in the context of one standardised cut-off value to guide asthma therapy is unlikely to be successful.

Acknowledgements The authors acknowledge the help of all the staff at The David Hide Asthma and Allergy Research Centre in undertaking the 18-year assessment and the generosity of the participants and their families of the 1989 Isle of Wight Birth cohort in being part of these assessments. Aerocrine kindly provided the exhaled nitric oxide consumables for the cohort assessment but they had no input into the study design or analysis of the data presented in this manuscript. ALK-Abello kindly supplied the skin prick testing reagents but again had no input into the study design or analysis of the data presented in the manuscript. 
Funding The 18-year assessment of the 1989 Isle of Wight birth cohort was funded by the National Institute of Health, USA (Grant5 R01 HL082925-02) and the British Medical Association.

Competing interests None.

Ethics approval This study was conducted with the approval of the Isle of Wight, Portsmouth and South East Hampshire research ethics committee (06/01701/34).

Provenance and peer review Not commissioned; externally peer reviewed.

\section{REFERENCES}

1. Alving K, Weitzberg E, Lundberg J. Increased amount of nitric oxide in exhaled air of asthmatics. Eur Respir J 1993;6:1368-70.

2. Kharitonov S, Yates D, Barnes P. Inhaled glucocorticoids decrease nitric oxide in exhaled air of asthmatic patients. Am J Respir Crit Care Med 1996;153:454-7.

3. Kharitonov S, Chung K, Evans D, et al. Increased exhaled nitric oxide in asthma is mainly derived from the lower respiratory tract. Am J Respir Crit Care Med 1996;153: 1773-80.

4. Jatakanon A, Lim S, Kharitonov $\mathrm{S}$, et al. Correlation between exhaled nitric oxide, sputum eosinophils, and methacholine responsiveness in patients with mild asthma. Thorax 1998;53:91-5.

5. Payne DNR, Adcock IM, Wilson NM, et al. Relationship between exhaled nitric oxide and mucosal eosinophilic inflammation in children with difficult asthma, after treatment with oral prednisolone. Am J Respir Crit Care Med 2001;164:1376-81.

6. Roberts G, Hurley C, Bush A, et al. Longitudinal study of grass pollen exposure, symptoms, and exhaled nitric oxide in childhood seasonal allergic asthma. Thorax 2004;59:752-6.

7. Roberts G, Mylonopoulou M, Hurley C, et al. Impairment in quality of life is directly related to the level of allergen exposure and allergic airway inflammation. Clin Exp Allergy 2005;35:1295-300.

8. Sippel JM, Holden WE, Tilles SA, et al. Exhaled nitric oxide levels correlate with measures of disease control in asthma. J Allergy Clin Immunol 2000;106:645-50.

9. Gelb AF, Flynn Taylor C, Shinar CM, et al. Role of spirometry and exhaled nitric oxide to predict exacerbations in treated asthmatics. Chest 2006;129:1492-9.

10. Smith AD, Cowan J0, Brassett KP, et al. Exhaled nitric oxide: a predictor of steroid response. Am J Respir Crit Care Med 2005;172:453-9.

11. de Jongste JC, Carraro S, Hop WC, et al. the CHARISM Study Group. Daily telemonitoring of exhaled nitric oxide and symptoms in the treatment of childhood asthma. Am J Respir Crit Care Med 2009;179:93-7.

12. Menzies D, Jackson C, Mistry C, et al. Symptoms, spirometry, exhaled nitric oxide, and asthma exacerbations in clinical practice. Ann Allergy Asthma Immunol 2008;101:248-55

13. Petsky HL, Cates CJ, Li AM, et al. Tailored interventions based on exhaled nitric oxide versus clinical symptoms for asthma in children and adults. Cochrane Database Syst Rev 2008;(2):CD006340.

14. Pijnenburg MW, Bakker EM, Hop WC, et al. Titrating steroids on exhaled nitric oxide in children with asthma: a randomized controlled trial. Am J Respir Crit Care Med 2005:172:831-6.
15. Shaw DE, Berry MA, Thomas M, et al. The use of exhaled nitric oxide to guide asthma management: a randomized controlled trial. Am J Respir Crit Care Med 2007;176:231-7.

16. Szefler SJ, Mitchell H, Sorkness CA, et al. Management of asthma based on exhaled nitric oxide in addition to guideline-based treatment for inner-city adolescents and young adults: a randomised controlled trial. Lancet 2008;372:1065-72.

17. Langley SJ, Goldthorpe S, Custovic A, et al. Relationship among pulmonary function bronchial reactivity, and exhaled nitric oxide in a large group of asthmatic patients. Ann Allergy Asthma Immunol 2003;91:398-404.

18. Franklin PJ, Taplin R, Stick S. A community study of exhaled nitric oxide in healthy children. Am J Respir Crit Care Med 1999;159:69-73.

19. Pearce N, Pekkanen J, Beasley R. How much asthma is really attributable to atopy? Thorax 1999;54:268-72

20. Kurukulaaratchy RJ, Matthews S, Arshad SH. Defining childhood atopic phenotypes to investigate the association of atopic sensitization with allergic disease. Allergy 2005;60:1280-6

21. Fullerton D, Britton JR, Lewis SA, et al. Helicobacter pylori and lung function, asthma, atopy and allergic disease: a population-based cross-sectional study in adults. Int J Epidemiol 2009;38:419-26.

22. Arshad SH, Stevens M, Hide DW. The effect of genetic and environmental factors on the prevalence of allergic disorders at the age of two years. Clin Exp Allergy 1993;23:504-11.

23. Kurukulaaratchy RJ, Waterhouse L, Matthews SM, et al. Are influences during pregnancy associated with wheezing phenotypes during the first decade of life? Acta Paediatr 2005:94:553-8.

24. Asher M, Keil U, Anderson $\mathrm{H}$, et al. International study of asthma and allergies in childhood (ISAAC): rationale and methods. Eur Respir J 1995;8:483-91.

25. Dreborg S. Skin tests for the diagnosis of IgE-mediated allergy. Allergy 1989;144 (Suppl 10):31-7.

26. American Thoracic Society. Recommendations for standardized procedures for the online and offline measurement of exhaled lower respiratory nitric oxide and nasal nitric oxide in adults and children - 1999. Am J Respir Crit Care Med 1999:160:2104-17

27. Taylor DR, Mandhane P, Greene J, et al. Factors affecting exhaled nitric oxide measurements: the effect of sex. Respir Res 2007;8:82.

28. Travers J, Marsh S, Aldington S, et al. Reference ranges for exhaled nitric oxide derived from a random community survey of adults. Am J Respir Crit Care Med 2007; 176:238-42.

29. Kovesi T, Kulka R, Dales R. Exhaled nitric oxide concentration is affected by age, height, and race in healthy 9- to 12-year-old children. Chest 2008;133:169-75.

30. Olin A, Rosengren A, Thelle DS, et al. Height, age, and atopy are associated with fraction of exhaled nitric oxide in a large adult general population sample. Chest 2006;130:1319-25

31. Taylor DR, Pijnenburg MW, Smith $A D$, et al. Exhaled nitric oxide measurements: clinical application and interpretation. Thorax 2006;61:817-27.

32. Craig TJ, King TS, Lemanske RF Jr, et al. Aeroallergen sensitization correlates with PC20 and exhaled nitric oxide in subjects with mild-to-moderate asthma. J Allergy Clin Immunol 2008;121:671-7.

33. Haldar P, Pavord ID, Shaw DE, et al. Cluster analysis and clinical asthma phenotypes. Am J Respir Crit Care Med 2008;178:218-24. 